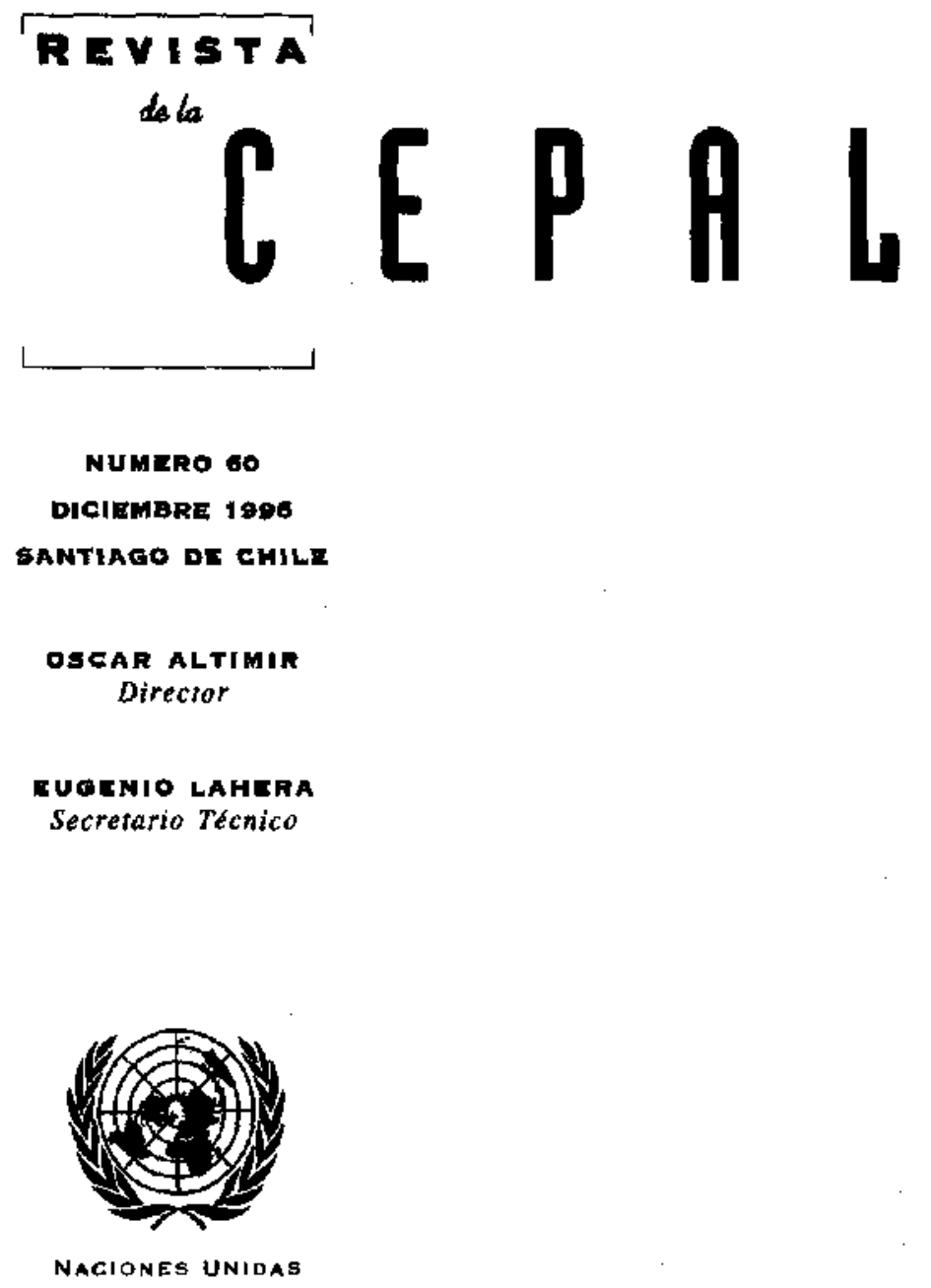


La evolución de las ideas y las políticas para el desarrollo

Gert Rosenthal

Políticas macroeconómicas para el crecimiento

Ricardo Ffrench-Davis

Flujos de capitales: lecciones a partir de la experiencia chilena

Eduardo Aninat, Christian Larrain

La transformación del desarrollo industrial de América Latina

José Miguel Benavente, Gustavo Crespi, Jorge Katz, Giovanni Stumpo

Las reformas de las pensiones en América Latina y la posición de los organismos internacionales

Carmelo Mesa-Lago

Aportes de la antropología aplicada al desarrollo campesino

John Durston

Prospección de la biodiversidad: potencialidades para los países en desarrollo

Julie M. Feinsilver

La inversión extranjera y el desarrollo competitivo en América Latina y el Caribe

Alejandro C. Vera-Vassallo

La crisis del peso mexicano

Stephany Griffith-Jones

Publicaciones recientes de la CEPAL 


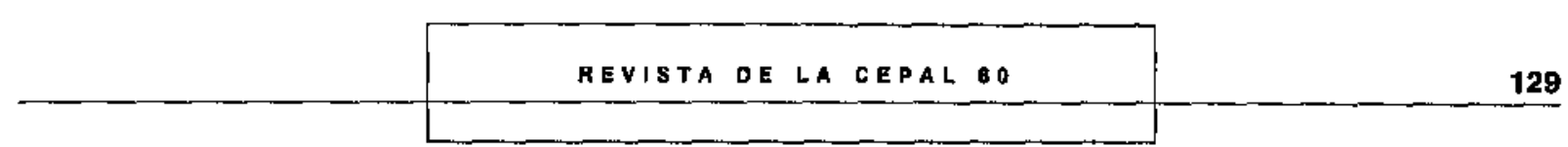

\section{La inversión extranjera y el desarrollo competitivo en América Latina y el Caribe}

\section{Alejandro C. Vera-Vassallo}

Jefe Unidad Conjunta CEPAL UNCTAI de

Empresas Transnacionales.

Division de Desarrollo

Productivo y Empresurial. CEPAL
Este artículo analiza el tratamiento a la inversión extranjera en el marco de la actual estrategia de desarrollo. Con ese fin examina la dinámica reciente de la inversión extranjera, tanto la directa como la indirecta, incluida la inversión de cartera y la cuasi accionaria, esta última referida a los contratos de transferencia de conocimientos productivos. Para ello se examinan los principales flujos de recursos y su direccionalidad, asi como los cambios ocurridos en las estrategias corporativas. Se concluye que es necesario articular una estrategia explicita de desarrollo y especificar como objetivo principal de la política de tratamiento a las inversiones extranjeras el de enriquecer el acervo de conacimientos tecnológicos de las economías receptoras. Esta política debe complementarse con otras referidas a la capacidad de absorción tecnologica, de modo de reforzar las capacidades de aprendizaje industrial y tecnológico, como fundamento de una fase de innovación endógena y de incremento dinámico de la competitividad internacional. 
I

\section{Introducción}

El foco del análisis que aquí se presenta es la importancia que adquiere la inversion extranjera en los parses de América Latina y el Caribe (ALC) en el primer quinquenio de la década de 1990, en el marco de las nuevas circunstancias regionales y mundiales.

No sólo han cambiado las modalidades de la inversión extranjera $\left({ }^{\prime} \mathrm{E}\right)^{1}$ y la composición de los flujos respectivos sino que, además, tanto la nueva inversión como la inversión acumulada (acervo) se han visto condicionadas por un nuevo escenario económico latinoamericano en el que el mercado y la empresa privada han asumido un papel protagónico, acorde con las medidas de liberalización y desregulación económica y con los propósitos de mejorar la competitividad del aparato productivo. Se pretende lograr una mayor y mejor insercion internacional y mantener un nivel creciente de actividad económica en el mediano y largo plazo. Este viraje estratégico de los países de ALC no puede desligarse del proceso de globalización ${ }^{2}$ de la economía mundial que marca con caracteres indelebles no sólo el diseño macroestratégico y político de los paŕses latinoamericanos sino que, además, incide de manera determinante en la lógica del comportamiento microeconómico de los agentes nacionales y extranjeros que operan en Alc.

El marco analítico está referido a la matriz de posibilidades definida por dos vectores complejos y di-

\footnotetext{
${ }^{I}$ En este artículo se consideran diversas modalidades de inversión extranjera. Además de la inversión extranjera directa (IED), que normalmente significa ampliación o creación de capacidad productiva (fonnación bruta de capital), existe la denominada inversión extranjera indirecta, es decir, aquella que no necesatianente implica mayor capacidad productiva. Tal es el caso de la inversión extranjera de cartera o portafolio (IEP), o sea acciones, bonos y depositos, y la inyersión extranjera cuasi accionaria (IEC) que no es otra cosa que contratos interempresariales de transferencia de conocimientos productivos (tecnologia, asistencia técnica, gerencia o administración, mercadeo, etc.). La IED genera como retorno utilidades, la IEP intereses o dividendos y la IEC regalías, derechos, comisiones, etc. La JEC también se conoce como "formas no convencionales de inversión que no suponen aporte de capital social" (non equity forms of investment).

${ }_{2}^{2}$ Para los efectos de este artículo, la globalización puede entenderse como un proceso cada vez más intenso de "producción internacional", concepto que comprende al conjunto de actividades que agregan valor, organizadas transnacionalmente por una firma que tiene la propiedad o el control (Dunning, 1993).
}

námicos - "realidad" y "estrategia"- que interactúan recíprocamente. Por un lado, la realidad económica latinoamericana a comienzos de la presente década fue moldeada por la vigencia prolongada de una estrategia de desarrollo sustentada en la industrialización sustitutiva de importaciones. Reestructurar esa realidad es el desafío de la hora presente en el contexto de la nueva economía mundial. Por otro lado, esa misma realidad exige un diseño estratégico y político que dé prioridad al mejoramiento de la competitividad internacional de las economías latinoamericanas, aumentando la complejidad y sofisticación tecnológica del aparato productivo e incrementando, por consiguiente, la productividad.

La industrialización sustitutiva model6 una firma industrial típica en la región que, en lo que se refiere a la inversión extranjera directa (IED), significó la creación de filiales "aisladas" que se acogieron a escalas y tecnologías consistentes con la existencia de mercados locales fuertemente protegidos y transacciones internacionales estrictamente reguladas y, en general, una política economica con un fuerte sesgo antiexportador que se trató de corregir en muchas ocasiones con medidas que no alteraban en lo esencial la lógica del modelo. La política vigente indujo en general una relación pasiva de estas filiales con sus fuentes de abastecimiento de bienes de capital, insumos y tecnología, que en su mayor parte se traducía en relaciones de carácter intrafirma.

Las filiales extranjeras en ALC mostraron una articulación insuficiente con el sector empresarial doméstico, de escaso desarrollo a su vez, asícomo con las respectivas estructuras institucionales de promoción de un desarrollo tecnológico endogeno, también escasamente desarrolladas. Estos efectos fueron más acentuados cuanto menores eran las dimensiones económicas del país receptor.

No hubo una formulacion estratégica y política clara en los países latinoamericanos que buscara deliberadamente la absorción social de conocimientos productivos, con el consiguiente proceso de aprendizaje industrial y tecnológico y la subsiguiente etapa de in. novación competitiva. Todo esto gravitó en contra de una inserción internacional más dinámica y cualitativamente superior de estos países. Cabe destacar que 
el legado más importante de este período ${ }^{3}$ es la plataforma industrial heredada que, en términos de IED acumulada, está constituida por empreses ubicadas en las actividades de mayor complejidad tecnologica o de mayor inserción internacional, y que son por lo tanto susceptibles de reestructuración industrial y desartollo competitivo.

El escenario latinoamericano de la primera mitad del decenio de 1990 se ha caracterizado por el intento generalizado de perfeccionar una nueva estrategia de desarrollo competitivo sustentada en un esquema institucional renovado que se expresa en un nuevo marco regulatorio en favor de la producción de bienes transables. Al mismo tiempo, la macroeconomía regional ha registrado la relajación de la tradicional restricción financiera externa y el inicio de la recuperación de los coeficientes de ahorro e inversión, muy afectados por la crisis de los años ochenta.

Pero para perfilar correctamente la realidad actual debemos colocar en el otro lado de la ecuación, además de las restricciones que a nivel microeconómico introdujo la industrialización sustitutiva, el deterioro institucional de la limitada capacidad tecnológica e innovativa de los países de la región (Vera-Vassallo. 1995a) así como las distorsiones en los precios fundamentales de la economía por la irrupción masiva de capitales extranjeros. Este sistema de precios, en lo que va corrido de la década actual, no parece evolucionar en forma plenamente convergente con el propósito de lograr una mayor y mejor inserción internacional.

En este contexto, aparecen dos variables institucionales que adquieren especial connotación en la matríz de posibilidades antes mencionada. Una se refiere a las modalidades y características de la transferencia internacional de tecnología. Otra es la capacidad social de absorción del progreso técnico de los países latinoamericanos. Hay modalidades de transferencia más eficaces que otras, pero su incorporación al aceryo de conocimientos de una economía determinada y de sus propias empresas depende de ciertas condiciones institucionales y de organización del propio país receptor.

El desarrollo argumental del articulo se sustenta en dos premisas de carácter conceptual pero susceptibles de verificación factual. La primera se refiere a la importancia de promover el desarrollo competitivo con

\footnotetext{
${ }^{3}$ Aunque América Latina mostró en el período 1945-1980 un crecimiento del pis per cápita de $2.7 \%$, superior al $2.5 \%$ postulado por la Alianza pana el Progreso en 1960 (Ramos, 1993).
}

una concepción sistémica del mismo ${ }^{4}$ (CEPAL, 1995a). La segunda, reconoce la relevancia de la contribución potencial de la inversión extranjera tanto a los procesos de inversión real como a la reestructuración competitiva e inserción internacional de las economías receptoras. Este reconocimiento se extiende a su vehrculo principal, las denominadas empresas transnacionales (ETs), las que han experimentado transformaciones importantes en sus estrategias y estructuras internacionales, en forma congruente con el surgimiento del nuevo orden económico internacional (CEPAL, 1995c).

El punto de partida histórico es la reinserción financiera latinoamericana que reinauguró un período en el que el ahorro externo podía complementar el ahoroo interno para financiar las exigencias de inversión que imponía, con mayor o menor premura, la reactivacion del desarrollo de los países de alc y la configuración de un nuevo escenario económico regional y mundial. Era preciso, por un lado, atender las demandas sociales postergadas durante la década de 1980 , en términos de ingreso y empleo productivo. De otro lado, había que poner énfasis en la tarea, iniciada desde la década anterior, de reestructurar el aparato productivo interno hacia niveles superiores de productividad y competitividad internacional.

El propósito principal de este artículo es destacar las nuevas características que adquiere el tratamiento a la inversión extranjera en los países latinoamericanos en el marco de una nueva estrategia de desarrollo productivo. Se pretende poner el énfasis en la necesidad de articular una estrategia explícita de desarrollo, una concepción sistémica en el diseño de las acciones y políticas pertinentes y un objetivo crucial como es el de enriquecer el acervo de conocimientos tecnológicos ${ }^{5}$ de las economías receptoras. En otras palabras, no se trata de promover la captación indiscriminada de activos financieros. Lo que se pretende es, sin desvirtuar el funcionamiento de los mercados, formular un marco regulatorio integral y compatible con el objeti-

\footnotetext{
${ }^{4}$ Se entiende por competitividad sisténica aquella que está íntimamente vinculada no sólo a las capacidades internas de la empresa misma sino también a la red de relaciones comerciales e institucionales de dicha empresa, las cuales afectan su grado efectivo de competitividad internacional. En este sentido, son importantes desde la infraestructura para la ciencia y la tecnologra y el sistema educativo nacional, así como los servicios de transporte, comunicaciones y energía (incluida la infraestructura fisica respectiva) hasta las relaciones interindustriales o interempresariales (reguladas por las normas de competencia), los servicios financieros, el sistema judicial y, en general, el ordenamiento institucional tanto público como privado del país.

"Se refiere a tecnologias "duras" (hardware) y "blandas" (sofware).
} 
vo de maximizar la transferencia internacional de conocimientos productivos que es la más importante contribución externa al desarrollo de las economías latinoamericanas. Lo anterior se hará de forma que esa transferencia encuentre una capacidad local de absorción tecnologica que permita no sólo incorporar el progreso técnico y difundirlo a todo el aparato productivo, sino que principalmente reforzar las capacidades de aprendizaje industrial y tecnológico como preludio imprescindible para la fase posterior de innovación endogena e incremento dinámico de la competitividad internacional.

II

\section{La inversión extranjera y el desarrollo competitivo en América Latina y el Caribe}

\section{La irrupción de capitales extranjeros en el úl- timo quinquenio}

La primera mitad de la década de 1990 ha sido testigo de la irrupción masiva de diversas modalidades de inversión extranjera (IE). Desapareció la restricción financiera externa agudizada por la crisis internacional de la deuda que incidió con particular gravedad en esta parte del mundo en desarrollo. Los ingresos netos de capitales ${ }^{6}$ provenientes del exterior en el período 1990 1994 han superado en promedio los 50 mil millones de dólares anuales, ${ }^{7}$ cifra muy superior al ingreso neto promedio anual del período 1987-1989 que fue inferior a 2.1 mil millones de d6lares estadounidenses. Los ingresos netos de capital extranjero a ALC casi se duplicaron en los primeros cuatro años de la presente década, llegando a superar los 63 mil millones de dólares en 1994 (cuadro 1).

Simultáneamente, se registraron importantes cambiós en su composición (cuadro 2), particularmente en lo que se refiere al predominio de las corrientes privadas de capitales extranjeros que a partir de 1990 superaron el $68 \%$ de los ingresos netos totales, llegando a $99.7 \%$ en 1994 . La inversión de cartera o portafolio

\footnotetext{
${ }^{6}$ Los ingresos o flujos netos son entradas de capitales públicos y privados de corto y largo plazo menos remesas de capital al exterior por concepto de desinversión 0 amortización de créditos exter nos. Este concepto es diferente al de saldo neto, usado en el balance de pagos, que equivale a la diferencia entre "ingresos y egresos netos" por un mismo concepto (por ejempla IED ingresada menos IED en el exterior). Este último es el que se usa en publicaciones anuales de la cEPal tales como el Balance Preliminar y el Estudio Económico.

${ }^{7}$ Incluye ingresos netos de inversión extranjera directa, inyersión extranjera de cartera o portafolio, finarciamiento oficial y créditos
} bancarios externos.
(IEP), que en 1990 era inferior at $4 \%$ de los ingresos netos totales, llegó a representar $62 \%$ en 1993 (42\% en 1994), siendo éste el cambio más relevante en el período analizado, tanto por los montos involucrados como por la aparición de nuevos mecanismos e instrumentos de captación. La IEP, constituida principalmente por bonos y acciones, crecí́ en términos netos más de 20 veces entre 1990 y 1994 ( 38 veces hasta 1993). La IED creció también en forma significativa y aumentó más de dos veces y media entre 1990 y 1994, o lo que es lo mismo, registro en dicho perfodo una tasa de crecimiento acumulativa anual superior al $27 \%$. Reapareció el financiamiento externo privado, con nuevas y diversificadas fuentes, y cesaron las transferencias netas de recursos financieros al exterior a partir de $1991^{8}$ (CEPAL, 1995d).

El financiamiento de fuentes oficiales, en términos netos, perdió significación en el período y los ctéditos bancarios privados oscilaron en torno a una media anual de 13.7 mil millones de dólares en el curso de la presente década (cuadro 1 ).

Un detalle muy importante para fines de formulación de política es que la participación de los ingresos netos de capitales de largo plazo, que superaba el $70 \%$ de los ingresos netos totales antes de 1990, pasó de $68 \%$ en 1990 a $58.8 \%$ en 1994 , habiendo llegado en 1992 y 1993 a cifras cercanas al $50 \%$ (CEPAL, $1995 \mathrm{c}) .^{9}$ Es decir, hubo una pérdida de participación de los capitales que tienen mayor incidencia en la in-

\footnotetext{
${ }^{8}$ En 1995, después de la crisis mexicana, se reiniciaron las tranşferencias netas de recursos al exterior.

${ }_{9}$ Incluye como ingresos netos de largo plazo: la red, el financiamiento oficial, la colocación de bonos a más de un afio y los créditos netos de largo plazo.
} 
CUADRO I

América Latlna y el Carlbe: Ingresos netos totales de capltal, 1990-1994

(Millones de dolares)

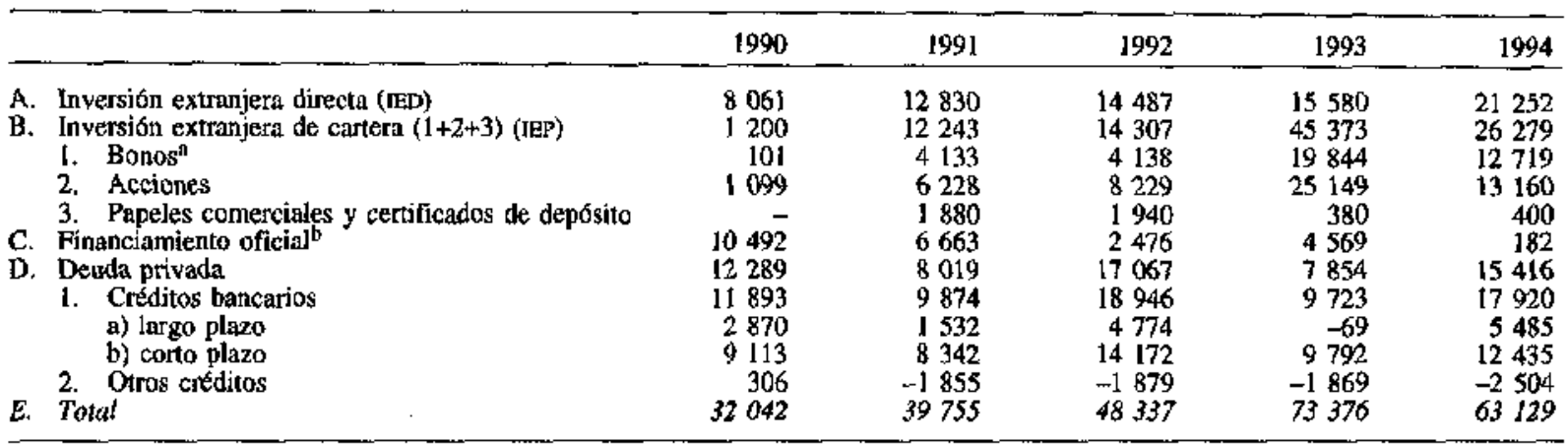

Fuente: Banco Mundial y Fondo Monetario Intemacional.

a Para los mismos años, el pMI sej̃ala ingresos brutos por 2760 (1990), 7242 (1991), 12577 (1992), 28794 (1993) y 18241 (1994) millones de dolares.

b Excluye cooperación técnica.

CUADRO 2

Amérlca Latina y el Caribe: Camblos en la composición de los ingresos netos de capital extranjero, 1990-1994

(Porcentajes)

\begin{tabular}{|c|c|c|c|c|c|}
\hline & 1990 & 1991 & 1992 & 1993 & 1994 \\
\hline $\begin{array}{l}\text { 1. Capitales extranjeros de origen privado } \\
\text { 2. Capitales extranjeros de largo plazo } \\
\text { 3. Inversión extranjera de cartera o portafolio (IEP) }\end{array}$ & $\begin{array}{r}67.2 \\
68.1 \\
3.7\end{array}$ & $\begin{array}{l}83.2 \\
58.6 \\
30.8\end{array}$ & $\begin{array}{l}94.8 \\
49.6 \\
29.6\end{array}$ & $\begin{array}{l}93.8 \\
51.9 \\
61.8\end{array}$ & $\begin{array}{l}99.7 \\
58.8 \\
41.6\end{array}$ \\
\hline
\end{tabular}

a Como porcentaje de los ingresos netos totales (cuadro 1).

b Incluye $A+B+D$ (cuadro 1 ).

incluye A+B.1+C+D.1.a.+D,2 (cnadro 1).

d Incluye $B(1+2+3)$ (cuadro 1).

versión real en favor de aquéllos de carácter especulativo y de más alta volatilidad.

Para los propósitos de este artículo es de la mayor importancia identificar los factores que están detrás de esta irrupción de capitales extranjeros que tiene nuevas características y abre nuevas perspectivas para el desarrollo de las economías latinoamericanas.

Una serie de factores, tanto internos como extrarregionales, explican la reactivación de los flujos internacionales hacia la región. Algunos son de naturaleza más estructural o permanente, como la creciente globalización productiva e internacionalización financiera y la consolidación progresiva de las reformas económicas e institucionales introducidas en la región. Otros son de naturaleza más coyuntural o transitoria, como los que tienen relación con la fase depresiva del cíclo económico de los paises industrializados y los programas de conversión de deuda externa y de priva- tización que se dieron en diferentes países de la región (CEPAL, 1995b).

Cabe señalar, no obstante, que según el balance de este quinquenio esa abundancia de capitales externos no se había reflejado proporcionalmente en mayores niveles de inversión real (CEPAL 1995a). Entre otras razones, porque muchos capitales que llegaron a América Latina estaban vinculados a cambios de propiedad de activos existentes ${ }^{10}$, fuera de la mencionada caída de la participación de los capitales de largo plazo en el total de capitales ingresados a la región. Además, el propio ahorro interno no tuvo una evolución favorable en el primer quinquenio de los años noventa. Di-

${ }^{10} \mathrm{En}$ una muestra, que incluye a los siete pafses más grandes, más del $40 \%$ de la lev ingresada a la región entre 1988 y 1993 se explica por programas de conversión de deuda externa (23\%) y privatización (17.8\%). (CEPAL 1995c, cuadro 11). 
CUADRO 3

Estructura regional de la inversión extranjera directa, 1990-1994 (Porcentajes)

\begin{tabular}{|c|c|c|c|c|c|}
\hline & 1990 & 1991 & 1992 & 1993 & 1994 \\
\hline $\begin{array}{l}\text { ALADI } \\
\text { Chile } \\
\text { México } \\
\text { MERcosur } \\
\text { Grupo Andino } \\
\text { Centroamérica } \\
\text { Caribe }\end{array}$ & $\begin{array}{r}90.0 \\
7.3 \\
32.7 \\
36.0 \\
14.0 \\
1.4 \\
8.6\end{array}$ & $\begin{array}{r}89.3 \\
4.1 \\
37.1 \\
28.2 \\
19.9 \\
3.8 \\
6.9\end{array}$ & $\begin{array}{r}91.4 \\
4.8 \\
30.3 \\
44.0 \\
12.3 \\
3.9 \\
4.6\end{array}$ & $\begin{array}{r}96.2 \\
5.4 \\
28.2 \\
50.1 \\
12.5 \\
-1.1 \\
4.9\end{array}$ & $\begin{array}{r}92.0 \\
8.4 \\
37.5 \\
21.7 \\
24.3 \\
4.4 \\
3.6\end{array}$ \\
\hline Total & 100.0 & 100.0 & 1000 & 100.0 & 100.0 \\
\hline
\end{tabular}

Fuente: Fondo Monetario Intenacional y fuentes nacionales.

chos capitales extranjeros, por un lado, financiaron en parte el crecimiento del consumo y, de otro lado, exhibieron una gran volatilidad, en especial aquellos captados a través de mecanismos no tradicionales de financiamiento externo ${ }^{11}$. Adicionalmente, en algunos países esta irrupción de capitales externos ha presionado negativamente sobre el tipo de cambio y la oferta monetaria, dando paso a una version renovada de vulnerabilidad externa de la región.

\section{LOS nuevos flujos de IED}

Con relación al renovado dinamismo de los ingresos de SED durante los primeros años de la década de 1990, se observa que, en 1994, los ingresos netos por este concepto alcanzaron una cifra del orden đe los 21 mil millones de dólares, muy superior a los volúmenes de los últimos años de la década anterior que giraban en torno a los 8 mil millones.

No obstante, es preciso destacar que hay países que despiertan mayor interés entre los inversionistas extranjeros (cuadro 3). En términos absolutos, los mayores flujos se han orientado como siempre hacia Argentina, Brasil y México, lo que pone de relieve la importancia de la dimensión de los mercados internos o de los mercados ampliados por acuerdos de integración (NAFTA, MERCosUR). De hecho, éste es un factor estructural de especial gravitación en las decisiones de las ETs, incluso por sobre las consideraciones macroeconómicas, como puede verificarse en el caso de Brasil (CEPAl, 1995c). Sin embargo, una rápida corre-

II Se refiere en general a la creciente bursatilización de las operaciones de financiamiento externo, a las diversas formas de inversión extranjera de portafolio (IEP) y a mecanismos tales como los ADR (American Depositary Receipts) y GDR (Global Depositary Receipts), entre otros. lación entre los flujos ingresados y la dimensión económica nos revela que las entradas recientes de IED a Brasil sólo representan entre el $20 \%$ a $30 \%$ de lo que le correspondería tradicionalmente por sus proporciones continentales. Asimismo, en los ingresos a Argentina durante los años noventa influyeron decisivamente los programas de conversión de deuda, y sobre todo, de privatización (CEPAL, 1995c). Ś́lo México y Chile muestran hasta 1993 una capacidad de atracción que excede proporcionalmente sus respectivas dimensiones económicas. También destaca como receptor importante Colombia que, al igual que Chile, experimenta un proceso de estabilización y ajuste más consolidado que otros países latinoamericanos o caribeños. En el otro extremo del espectro regional se encuentran los países de América Central y el Caribe que, en general, a pesar de que tienen la ventaja de la cercanía geográfica a Estados Unidos, al igual que México, y que han sido favorecidos por iniciativas estadounidenses de cooperacion y fomento al comercio y las inversiones, no han despertado igual interés en los capitales externos. Se exceptúan Costa Rica y República Dominicana en lo que se refiere a las zonas de procesamiento de exportaciones (mayormente maquila) que cobraron importancia a partir de fines de la década pasada debido a significativos incentivos tributarios y arancelarios.

El análisis de la IED según origen geográfico muestra siempre el predominio de los países desarrollados, así como un dinamismo creciente en la participación de países en desarrollo, en especial de la propia región, y la aparición de nuevos socios extranjeros como Nueva Zelandia, Australia, España y Canadá. Japón y las economías de reciente industrialización del Asia tienen todavía escasa presencia en ALC.

Algunas empresas latinoamericanas líderes están realizando inversiones en otros parses de ALC (IED en el exterior), sobre todo como resultado de las oportuni- 
đades que han abierto a los inversionistas latinoamericanos los programas de privatización (CEPAL, 1995a). De esta manera, pareciera que está surgiendo un nuevo actor en el escenario regional. Se trata de la empresa transnacional latinoamericana (ETL) que, si bien tiene antecedentes lejanos en el tiempo, aparece ahora con más fuerza y perspectivas en el curso de los años noventa. Al parecer, las empresas latinoamericanas líderes han decidido adoptar los patrones de comportamiento propios de la era de la globalización. Estas inversiones intrarregionales o intracontinentales y sus efectos derivados en términos de comercio de bienes y servicios ${ }^{12}$ están dando paso a un proceso de integración económica regional por razones de mercado que, en forma creciente, está acompañando la voluntad política de los gobiernos de la región. Esta se expresa en la proliferación de acuerdos y convenios de integración y cooperación económica a escala continental (CEPAL, 1994).

Las entradas de IED y la actividad de las ETs cumplen un papel importante en la vinculación de las economías receptoras con las redes integradas de producción internacional y su desarrollo, las cuales sin duda constituyen el eje central del proceso de globalización de la economía mundial. Las ETs, a través de sus operaciones de IED, movilizan sus activos tangibles $\mathrm{e}$ intangibles (capital, patentes tecnologicas, prácticas organizacionales y gerenciales, vínculos comerciales, etc.) con el proposito de incrementar su competitividad internacional y su rentabilidad global, con efectos directos en la capacidad del país receptor para producir bienes y servicios de mejor calidad y en mayor cantidad. Estos flujos de ingreso, por esas mismas razones, constituyen una de las modalidades de inversion extranjera con mayor capacidad potencial para estimular los procesos de formación bruta de capital y de acumulación de conocimientos productivos en la economfa receptora, así como también para posibilitar la vinculación de las empresas domésticas a las redes de producción y abastecimiento de las ETs y beneficiarse del acceso a los mismos activos tangibles e intangibles disponibles en el sistema corporativo transnacional. ${ }^{13}$ Al mismo tiempo, con relación a las empresas latinoamericanas que invierten en el exterior, la movilización

\footnotetext{
${ }^{12} \mathrm{El}$ comercio intrarregional se ha expandido notablemente durante los primeros cinco afios de la presente década, llegando casi a duplicar su tasa de participación en el comercio total de alc.

${ }^{13}$ Un número creciente de firmas de diversos países están sujetas a estrategias corporativas integradis a escala internacional que involucran no sólo a empresas matrices sino también filiales domésticas y extranjeras, lo que constituye un "sistema corporativo transnacional".
}

de activos semejantes fortalece a las economías de origen al viabilizar el acceso de dichas empresas tanto a las tecnologlas y capacidades de investigación y desarrollo (I\&D) disponibles en el extranjero como a los mercados externos, a través de las ventas locales de sus filiales, transacciones intrafirma y otras actividades comerciales derivadas.

\section{La dlstribución sectorial de la IED acumulada: bases para una reestructuración competitiva}

El acervo de IED en el sector primario es poco significativo en la mayoría de los países latinoamericanos y caribefios, no obstante la abundancia de recursos naturales. Lo anterior tiene directa relación con la ola de nacionalizaciones que tuvo lugar en la región entre los años sesenta y setenta que además de abarcar las actividades extractivas se extendió también a la actividad bancaria y los servicios públicos (Sigmund, 1980). Sin embargo, a partir de fines de los años ochenta en Chile y en el curso de la presente década para el resto de países de la región, la reforma económica ha abierto importantes oportunidades de inversión extranjera en las actividades de extracción y explotación de recursos naturales (mineros, petroleros, pesquetos, agxícolas y forestales) y en las actividades secundarias y terciarias vinculadas a travếs de eslabonamientos productivos de diversa índole.

La mayor parte del acervo de IED en ALC se encuentra en el sector manufacturero, lo que es explicable tanto por la prolongada vigencia del modelo sustitutivo de importaciones como por el mismo proceso de nacionalización de la explotación de recursos naturales al que se aludio anteriormente. La política vigente en la mayoría de los países de la región incluyó hasta la década pasada restricciones explícitas a la UED no sólo en el sector primario sino también en el sector financiero y otros servicios. En la mayoría de esos países la IED se localiza en las industrias productoras de bienes de consumo masivo destinados a los mercados internos, en especial en las ramas de alimentos, bebidas y tabaco, pero también en actividades de mayor contenido tecnológico como química básica, metalmecánica, electro-electrónica, etc. Este desarrollo industrial alcanza diversos estadios de sofisticación tecnológica que, evidentemente, son superiores en los países de la región de mayores dimensiones económicas o, lo que es lo mismo, de mayor desarrollo económico relativo.

En la década de 1970 y los primeros años de la década de 1980 se inició una recomposición de la 
industria regional en favor de las ramas manufactureras que utilizan en forma intensiva recursos naturales. Al respecto, se puede mencionar: celulosa y papel, petroquímica, aluminio, aceites vegetales, harina de pescado, entre otras. Es decir, ramas productoras de bienes básicos, altamente estandarizados, de uso difundido (industrial commodities), intensivos en capital, con tecnología moderna y accesible, procesos de producción de flujo continuo y grandes economías de escala. En estas ramas convergen empresas de propiedad local (consorcios nacionales), especialmente en los países más grandes de la región, y filiales de empresas extranjeras (Katz, 1995). Esta recomposición, en el período mencionado, tiene explicaciones distintas en los diferentes países de la región. En Chile se explicaba por una temprana mudanza de su estrategia de desarrollo. En Argentina y Brasil, estas inversiones respondían todavía al modelo sustitutivo pero estas economias se ven impulsadas a exportar frente a la drástica contracción de la demanda interna en el curso de los años ochenta. En Perú, se puso en marcha un proceso deliberado de industrialización, con criterio sustitutivo, que daba prioridad a la industria básica en manos del capital nacional, privado o estatal.

Durante la crisis de los años ochenta, el sector manufacturero latinoamericano disminuyó significativamente su capacidad de atraer a los inversionistas extranjeros. Tras diversos esfuerzos de racionaización se producen a fines de la década algunos tímidos intentos de reestructuración incustrial de las filiales manufactureras con la finalidad de adecuarse al nuevo escenario económico. El agotamiento de la industrialización sustitutiva en la mayorra de los países de la región, ${ }^{14}$ los períodos de crisis y estabilización subsiguiente y el ínicio de la reforma económica tienen una secuencia temporal diferente en los distintos países de la región. ${ }^{15}$ En el curso de esta đécada se fueron fortaleciendo las zonas de procesamiento para la exportación y se aplicaron medidas especificas en favor de la subcontratación, especialmente en México y países centroamericanos y caribeños (plantas maquiladoras).

Los años noventa son testigos de una nueva fase de expansion selectiva de la industria regional y de

\footnotetext{
${ }^{14}$ Estos 8fntomas fueron menos evidentes en los países grandes de la región, especialmente Brasil.

${ }^{15}$ En Chile la crisis y la recesión se inician en el segundo semestre de 1973, en Argentina a partir de 1978. en Brasil desde 1981 y en México en 1982 con fuertes repercusiones en el resto de los palses de la región.
}

esfuerzos cada vez mayores de reestructuración de la plataforma industrial heredada del modelo sustitutivo. En el curso de la presente década maduran secuencial y progresivamente los esfuerzos de estabilización económica y de reforma estructural, en el marco de una nueva estrategia de desarrollo en la región que favorece nuevas modalidades de inserción de las ETs en la economía regional. Todo lo cual fortalece la competencia, tanto interna como externa, la que adquiere mayor importancia como factor determinante del comportamiento microeconómico.

Este nuevo contexto regional evidencia las debilidades competitivas que acarreó el modelo sustitutivo, en general. Pero en especial, en las economías pequeñas y medianas de la región donde la industrialización, al amparo de la protección de los reducidos mercados internos, se tradujo comparativamente, en escalas menores, en grados menores de sofisticacion tecnológica, en niveles más bajos de aprendizaje industrial y, en forma congruente, en un desarrollo institucional menor en la esfera de la innovación tecnologica. El proceso derivado de la lucha por la supervivencia adquirió relevancia especial en las filiales extranjeras localizadas en los sectores de mayor sofisticacion tecnológica o en los segmentos nás dinámicos de la demanda interna de productos manufacturados. Frente a la apertura externa de la economía, las filiales de empresas extranjeras, así como las propias empresas nacionales existentes, en particular de las ramas automotriz y metalmecánica, encuentran imposible mantener el grado de integración vertical y el modelo de organización industrial de periodos anteriores y reaccionan tratando de buscar la especialización y la desverticalización, y, en consecuencia, elevando los coeficientes de importacion y reduciendo la producción local de bienes intermedios (Bielschowsky y Stumpo, 1995, y Katz, 1995).

En el curso de la presente década, estos hechos conducen a impactos sectoriales diferenciados en las economías latinoamericanas. A consecuencia de los cambios en el marco regulatorio y el régimen de incentivos, en algunos páses como Argentina, Brasit, México, Colombia, la nueva macroeconomía regional tegistró caídas en la tasa de interés real y en los precios relativos de los bienes de consumo durables y los automoviles, to que combinado con algunas medidas complementarias explicaría la reactivación de la demanda interna de estos bienes, en particular autonóviles (Katz, 1995). Esto se conjuga con las estrategias corporativas de las ETs globalizadas de la rama auto- 
motriz en los países más grandes de la región ${ }^{16} \mathrm{La}$ desinversión en este sector, en el caso de paises medianos como Chíle y en especial Perú, entre otros, fue mucho mayor y en algunos casos no queda más que e] recuerdo de estas actividades cuyos conocimientos tecnologicos no fueron absorbidos por el país respectivo.

Simultáneamente, se produce una declinación de otras ramas de la industria latinoamericana que hacen uso intensivo de conocimientos y tecnología. Es decir, a la declinación de la rama metalmecánica, se suma la de la electro-electrónica, ramas donde las ETs tienen una presencia preponderante, en particular en los pafses de menores dimensiones económicas de la región. Frente a la disyuntiva de reestructurarse o perecer, en muchos casos éstas optaron por desinvertir (Bielschowsky y Stumpo, 1995, cuadro 2).

El aumento de la IED en los servicios y su caída en las manufacturas durante los afios ochenta se tra- dujo en un aumento de la participación relativa del acervo de capital extranjero acumulado en lactor terciario. La IED en servicios como el comercio, y el transporte y las comunicaciones, surge inicialmente como apoyo a las actividades de las ETs en el sector manufacturero. La reforma económica en la región significo la eliminación de las restricciones a la $E D$ en algunas actividades de servicios, particularmente en bienes raíces, finanzas y seguros, lo que unido a la maduración de los mercados de capitales, en el contexto de la apertura, ha favorecido el ingreso de capitales externos a estas actividades (bancos, actividades de leasing, corredores de valores y seguros, franquicias, entre otras). Otro factor importante del crecimiento de la IED en este sector, durante los años noventa, son los programas de privatización (electricidad, telecomunicaciones, etc.), lo que en conjunto marca una tendencia de la IED en los años noventa con consecuencias evidentes en el acervo correspondiente.

\section{III}

\section{Las empresas transnacionales en}

\section{el escenario económico mundial}

\section{La distribuclón Internacional de la IED}

El mapa de la IED en el mundo está experimentando cambios significativos y al mismo tiempo su vehículo principal, la empresa transnacional, ha sufrido transformaciones importantes en sus estrategias y estructuras internacionales concomitantemente con el surgimiento de un nuevo orden económico internacional.

La revitalización de las entradas de EED a ALC coincide con las tendencias observadas a nivel mundial. Los países en desarrollo muestran una capacidad cada vez mayor para atraer capitales extranjeros en el curso de los años noventa, pasando de un ingreso equivalente al $18 \%$ del flujo total de uro en el período 1987.

\footnotetext{
${ }^{15}$ Durante los años finales de la década de 1980 las estrategias corporativas de las ETs del sector automotor buscan mejorar su competitividad en el interior del mercado norteamericano mediante estrategias que persiguen abaratar los costos a través de sus filiales en México (Mortimore, 1995b). En el caso de Argentina y Brasil, cuyo sector automotor tuvo nuchas dificultades en los afios ochenta, se buscaron soluciones por medio de acuerdos sectoriales en et contexto del MerCosur y otras acciones de estrategia corporativa, como la creación de la empresa binacional autolatina (Ford y Volkswagen).
}

1991 a $37 \%$ de los flujos mundiales en 1994. Los pajses desarrollados, por el contrario, pasan de captar $82 \%$ en el período $1987-1991$ a $60 \%$ en 1994 del total de ingresos de IED en el mundo (UNCTAD, 1995).

Con respecto a esta creciente captacion de IED por parte del mundo en desarrollo cabe subrayar dos cosas: primero, que el repunte de los países en desarrollo, sobre todo durante los últimos tres años, coincide con la reactivación de la IED hacia ALc. La región, después de la crisis de los años ochenta cuando pierde participacion a favor del Asia en desarrollo, ha mostrado una clara recuperación en el curso de los años noventa aunque sin alcanzar aún los porcentajes de captación anteriores a la crisis (Mortimore, 1995a). ${ }^{17}$

\footnotetext{
${ }^{17}$ En el período 1975-1979 la regíón capta anualmente, en promedio, el $13 \%$ de los flujos totales de ingreso de IED y el Asia en desarrollo, alrededor del $5 \%$. En la segunda mitad de los affos ochenta, la participación de ALC cayó a $6 \%$, promedio anual, del total mundial mientras que el Asia en desarrollo llego hasta cerca del 9\%. En los prineros cuatro años de los años noventa la región se recupera hasta captar el $9 \%$ de los ingresos mundiales de ieD pero la participación del Asia en desarrollo continúa creciendo hasta cerca del $15 \%$ al afto en promedio.
} 
Segundo, que dentro del Asia en desarrollo destaca nítidamente la fuerza de atracción de China, sin duda atribuible a las dimensiones colosales de su mercado interno y a una reforma económica que promueve la inversión extranjera no obstante que continúa el dirigismo estatal.

\section{Los cambios en las estrategias corporatives}

Por su tamanio y la naturaleza de sus actividades, las ETs surgen a fines del siglo $\mathrm{XX}$ como actores protagónicos de una economía mundial liderada por la tecnologfa y selectivamente globalizada.

Estas empresas han asumido crecientemente un papel de liderazgo en el proceso de globalización de la economía mundial por su presencia protagónica en sectores y mercados clave. ${ }^{18}$ Las ETs son el agente económico relevante en la mayoría de las transacciones internacionales de mayor dinamismo (comercio internacional, finanzas internacionales, transferencia internacional de tecnología y otros conocimientos productivos, etc.). Un tercio de la producción mundial pertenece a la esfera de actividad de las ETs, que comprende matrices y filiales en el exterior. En 1993, el volumen de las ventas totales de las filiales extranjeras de ETs ( 5.2 billones de dolares) excedió el det comercio mundial de bienes y servicios no financieros (4.7 billones). De otro lado, más de la mitad del comercio mundial es expresión de las actividades comerciales de las ETs y una parte significativa de dicho comercio mundial es intrafirma (UNCTAD, 1994a y 1995).

Algunos indicadores importantes al respecto son la existencia de alrededor de 40000 matrices de ETS y 250000 filiales extranjeras, decenas de miles de alianzas estratégicas, cientos de miles de acuerdos de subcontratación, sin contar otros contratos interempresariales para fines de transferencia de conocimientos productivos (Naciones Unidas, 1992; Finkman y Montenegro, 1995). En este contexto, los procesos de toma de decisiones sobre producción, comercio de bienes y servicios, flujos de tecnología y de capital, movilidad internacional de profesionales calificados y acuerdos interempresariales, están todos interconecta-

\footnotetext{
${ }^{18} \mathrm{La}$ 18D, a nivel mundial, creció entre 1983 y 1990 con una rapidez cuatro veces mayor que la producción mundial y tres veces mayor que el comercio mundial (Morán, 1991). Durante 1991-1993 el acervo (stock) mundial de IED creció tan rápidamente como las exportaciones mundiales de bienes y servicios y una vez y media más rápido que el producto interno bruto mundial (UNCTAD, 1995),
}

dos en un complejo y creciente entramado internacional que no es sino la expresión concreta del surgimiento de un sistema internacional integrado de producción.

Este proceso de globalización de la economía mundial, entendido como una internacionalización cada vez mayor de la actividad empresarial, fue, sin duda, desencadenado por una notable aceleración del desarrollo tecnologico, principalmente de las tecnologías de información, que precipitaron cambios esenciales a nivel de la organización industrial, del comportamiento y de la estructura de la firma y, en consecuencia, de las estrategias corporativas correspondientes.

Repensar el escenario económico latinoamericano con el proposito de formular estrategias y políticas de desarrollo exige necesariamente entender y conocer como se han reconfigurado las estrategias y las estructuras organizativas de las ETs con la finalidad de poder articular sistemas integrados de producción a nivel internacional. Es importante destacar que las mismas estrategias que se aplicaban antes tienen en la actualidad impactos diferentes en las economías de ALC, hoy más complejas y abiertas y con un nuevo estilo de desarrollo.

Durante la vigencia del modelo de industrialización sustitutiva en la región, la eT matriz se vinculaba a una constelación de filiales en el exterior, cuya estrategia de operación consistía en mantenerse solas (stand-alone strategy), diseñadas para abastecer a la casa matriz con recursos naturales o servir a los mercados locales con bienes manufacturados o servicios, reproduciendo los mismos productos de la empresa matriz. Esta era usualmente la fuente del capital, las prácticas administrativas y los conocimientos tecnologicos. Esta fue la modalidad de organización predominante de las ETs que llegaban a la región en forma de enclaves mineros o plantaciones agrícolas; es decir, desarticuladas del resto del aparato productivo nacional, lo que se explica por dos razones fundamentales: el escaso grado de sofisticación tecnoproductiva de las economías receptoras y la excesiva protección del mercado interno asociada al modelo sustitutivo. Fue también el caso de las industrias de sustitución, que intentaban replicar la matriz a una escala reducida.

Las mismas presiones derivadas del proceso de globalización, en particular el progreso técnico y la liberalización economica, modificaron progresivamente la forma en que se estaba emprendiendo la producción internacional en la región y en el mundo. La competencia de los costos de los productos estandarizados, la convergencia de los patrones de consumo a nivel 
intemacional y la reduccion de los costos de transporte terminaron por ampliar el alcance geográfico de las estrategias corporativas. Las grandes firmas oligopólicas a nivel internacional (industria automotriz y electrónica) fueron capaces de combinar economías de escala con la organización de abastecedores de bajo costo a nivel internacional. Esto condujo a la adopción de estrategias de integración simple según las cuales las filiales, con tecnología proporcionada por la casa matriz, emprendían un rango limitado de actividades orientadas a proveer de insumos especificos a la misma matriz. Esta última se convierte así en la coordinadora de los distintos usos que da a los recursos el entramado cerrado de filiales. Se fortalecieron, de esta forma, las relaciones de subcontratación que en la región aparecen sobre todo durante la década de los años ochenta cuando se promueven las zonas de procesamiento de exportación y la industria maquiladora, como se vio anteriormente. Las ETs, en determinados países de la región, ensayaron estrategias de integración simple en la industria automotriz y electrónica, que después evolucionaron tímidamente hacia estrategias de integración compleja.

Una característica de los dos tipos de estrategias mencionados era que la produccion al interior de la $E_{T}$ permanecía fragmentada y la internacionalización de la actividad productiva a traves de las fronteras era limitada. Finalmente, la creciente liberalización de las transacciones económicas internacionales y el incremento de la competencia internacional así como la difusión de las tecnologías de información condujeron hacia estrategias de integración compleja en donde las ETs asumen el papel de organizadoras de la producción y de las transacciones dentro de una red transnacional, de relaciones internas y extes.' ' $\$$, que pueden o no implicar participación accionaria pero que sirven los intereses globales de la ET. La matriz es el centro de una red de actividades interdependientes pero menos formalmente dirigidas (UNCTAD, 1994b).

Al amparo de estas modalidades estratégicas y de organización, la producción internacional liderada por las ETs no \$6lo traslada bienes y servicios a través de las fronteras, sino también factores productivos, métodos de organización, conocimientos tecnológicos, con arreglo al esquema de una estructura administrativa unificada, dando lugar a una división internacional del trabajo intrafirma. Desde esta perspectiva, las ETs, con sus estrategias cada vez más complejas, favorecen un cambio cualitativo de la economía mundial, influyen en la división internacional del trabajo, fomentan la complementariedad del comercio exterior y la inversión extranjera y son los principales motores del crecimiento y desarrollo en el nuevo orden económico internacional. Anteriormente, la inversión extranjera y el comercio exterior eran formas alternativas para el abastecimiento de los mercados externos. Actualmente se observa una correlación creciente entre ambas variables, especialmente en los paises desarrollados, pero se reconoce que las redes de filiales integradas a escala regional son un factor determinante importante del crecimiento del comercio intrarregional.

Sin embargo, al parecer se está poniendo excesivo énfasis en la reflexión anterior sobre el tránsito de las ETs hacia estrategias complejas y estructuras globales, sobre todo en el caso de alC y de los países en desarrollo en general. La globalización es un fen6meno a escala mundial que normaimente se asocia a estrategias corporativas de integración compleja. Sin embargo, estas estrategias se han dado sólo en determinados sectores, que utilizan conocimientos y tecnología en forma muy intensiva, mientras que otros continuan operando con los esquemas anteriores de standalone y de integración simple. En la región, las ETs estarian comenzando a ensayar las denominadas estrategias de integración compleja sólo en los páses más grandes que tienen IED en industrias como la automotriz y la electro-electrónica.

\section{Los patrones de comportamiento de las ETS}

Al comparar el comportamiento de las ETs que operan en el Asia en desarrollo y en América Latina se observa que existen patrones diferenciados según el origen geografico del capital, los que inciden de manera distinta en las oportunidades de estas dos regiones para lograr un desarrollo competitivo y una mayor inserción internacional (Mortimore, 1995a). En el Asia en desarrollo operan preponderantemente empresas transnacionales de origen japonés, mientras que en América Latina se han establecido, en primer lugar, ETs de origen estadounidense $y$, en segundo lugar, europeo. Existen diferencias de comportamiento importantes entre las ETs de Estados Unidos y las de Japón no sólo en cuanto a preferencia geográfica sino a control patrimonial. Las ETs estadounidenses tienen una participación mayoritaria en el capital de las filiales que operan en ALC, mientras que las ETs japonesas en el Asia en desarrollo prefieren participaciones minoritarias en sus filiales y otras formas de asociación mediante relaciones de subcontratación o concesión de 
licencias. ${ }^{19}$ La experiencia del Asia en desarrollo, en especial de la República de Corea y la provincia china de Taiwán entre los cuatro tigres, ${ }^{20}$ parece demostrar que la estrategia de asociación con las ETs o, lo que es lo mismo, la modatidad de IEC, ha tenido la ventaja de facilitar un proceso nacional de aprendizaje industrial y absorción tecnológica que hizo posible pasar de la fase de adaptación y asimilación a la fase de posterior innovación y competencia con sus propios progenitores, incorporándose de este modo a la nueva economía internacional y su dinámica competitiva.

El interés de las ETs en el uso de sus activos tangibles e intangibles es promover su presencia internacional bajo diversas modalidades de inversión extranjera en la medida que éstas sean compatibles con sus objetivos de maximizar la tasa de ganancia. Si éstas llegan a externalizar y comerciar conocimientos productivos (IEC), se produce una transferencia de tecnologfa de la que se benefician empresas y países receptores, dependiendo del grado de desarrollo institucional de estos últimos. Pero si las ETs emprenden actividades de IED a través de filiales controladas por la ma- triz, entonces se produce esencialmente una transferencia intrafirma de tecnología y la absorción y difusión al interior del país receptor es mucho más limitada, como se verá más adelante.

Del examen de estos patrones de comportamiento de las ETs se concluye que la transferencia efectiva de tecnología a partir de las diversas actividades de las ETs no es un proceso que se produce automáticamente ni mucho menos una consecuencia de propósitos inherentes a las estrategias corporativas. Por el contrario, debe ser un objetivo deliberado y explícito inscrito en las estrategias gubernamentales que contemple tanto un esfuerzo de desarrollo tecnologico interno, en procura de efectos multiplicadores de causación circular, ${ }^{21}$ como la formulación de polfticas activas encaminadas a maximizar la transferencia de tecnología a partir de las diversas modalidades de inserción de las actividades de las ETs en los países latinoamericanos, y de las iniciativas locales de asociación y articulación con las ETs. Esto debe hacerse de manera de lograr que el entramado de sus redes regionales pase por las actividades nacionales de las economías receptoras.

\section{Bases para el diseño estratégico y de política económica}

\section{Referenclas teóricas sobre la inversión y la tecnología extranjeras}

Como una de las tantas consecuencias del proceso de globalización-transnacionalización de la economía mundial, ha vuelto a despertar el interés por las teorías relativas a la empresa transnacional y a la producción internacional. Es probable que una razón igual-

\footnotetext{
${ }^{19}$ En el caso de las ETs estadounidenses y europeas fabricantes de automóviles que operaban en países en desarrollo, un $85 \%$ de su capacidad productiya se concentraba en América Latina mientras que la de sus homólogas japonesas en los países asiáticos en desa rrollo llegaba a $89 \%$. A su vez, la mayor parte de la capacidad productiva de las primeras ( $88 \%$ ) correspondía a filiales con participación mayoritaria del capital extranjero, en ranto que trarándose de las ETs de Japón se traducía casi exclusivamente en filiales con participación minoritaria del capital nipón o IEC japonesa sin participación en el control de la empresa.

${ }^{20}$ Dejendo de lado los casos de las ciudades-estados Hong Kong y Singapur.
}

mente importante haya sido la aparición cel análisis de internalización ${ }^{22}$ que rápidamente ha pasado a ocupar un lugar prominente en el plano de la teoría económica y en especial en la teoría de la organización industrial.

Hoy la preocupación de los gobiernos de la región pone especial énfasis en crear las condiciones para atraer flujos cada vez mayores de capital extranjero y de esta forma sentar las bases para incorporar al país al proceso de globalización y evitar su marginación del

\footnotetext{
${ }^{21}$ Es decir, el propio mejoramiento de los indicadores de desartollo tecnológico doméstico, incluida la calificación de la mano de obra, refuerza la capacidad de atraer IE con mayor contenido tecnológico, lo que a su vez repercute en la elevación de los niveles tecnológicos internos.

${ }^{22}$ El análisis de internalización de mercados establece que las ETs derivan de los altos costos naturalmente asociados a las transacciones de jnercado (fallas naturales de mercado). Esto obliga a las ETs a internalizar estas operaciones como un recurso institucional para ahorrar en dichos costos.
} 
nuevo orden económico mundial. Este artículo no pretende hacer una revisión de las điferentes teorías existentes que podrían sustentar una solución a estas preocupaciones, pero sí considera pertinente alertar a los formuladores de políticas sobre las implicancias de la vertiente teorica a la cual se adscriben deliberada o implícitamente. Es decir, si alguien se basara en la postura convencional "estructura-desempeño" del análisis de organización industrial, según la cual las grandes corporaciones son las causantes de las imperfecciones del mercado, las polf́ticas se orientarfan hacia la intervención estatal; pero si se considera que las ETs son la solución a las fallas de mercado, entonces los gobiernos deberían eliminar sus políticas hostiles a dichas empresas (Pitelis y Sugden, 1991).

Cantwell (1991) hace una revisión de las diferentes teorías de la producción internacional que han sido desarrolladas en los últimos 30 años. El las clasifica en cinco grupos. Dos de ellos se refieren a diferentes alternativas teoricas de la firma. El tercero se basa en el análisis de las industrias internacionalmente competitivas. El cuarto incluye análisis macroeconómicos que pretenden explicar la actividad transnacional. El quinto integra diversas teorfas parciales en un marco coherente y comprensivo, el denominado "paradigma ecléctico", incluidas las recientes reformulaciones de Dunning (1993), que puede aplicarse a nivel micro, meso o macroeconómico y que puede servir de base conceptual de referencia, sin perjuicio de investigaciones teóricas más amplias.

El paradigma ecléctico ofrece un marco general para determinar el grado y patrón de comportamiento de la producción doméstica de propiedad de empresas extranjeras como de la producción en el exterior a través de empresas del propio país. No es propiamente una teoría de la empresa transnacional per se, sino de las actividades de las empresas involucradas en cadenas de valor agregado organizadas internacionalmente. Para eso es necesario entender y explicar por que se produce una operación de $\mathrm{IED}$.

De manera simplificada se puede decir que dicho paradigma distingue entre las ventajas de propiedad (referida a aquellos activos tangibles o intangibles de la ET que le permiten posicionarse mejor que una empresa doméstica en un mercado potencial dado); ventajas de localización (referida a recursos naturales, humanos o institucionales cuyas características justifiquen la produccion local) y ventajas de internalización (que explican por qué es mejor ampliar la estructura corporativa - creando una filial dentro de determinado mercado- antes que abastecerlo vía exportaciones).
En el contexto del paradigma ecléctico y de la nueva teoría de la firma, si una ET posee un activo (por ejemplo, una patente industrial), para incrementar sus ventas globales y captar un porcentaje de determinado mercado extranjero, puede optar por una de tres alternativas: exportar, licenciar (a una empresa local en el país extranjero vía IEC) 0 invertir (crear una filial en dicho país vía IED). El dilema entre exportar o licenciar se define por consideraciones relativas a la naturaleza contractual de la operación. La primera es de corto o mediano plazo; la segunda es de largo plazo pero conlleva la pérdida de la propiedad a control del activo (en este caso conocimientos tecnológicos). La decision de invertir, especialmente si la ET no quiere perder el control del activo, dependerá del balance entre los costos de transacción en el mercado (exportar) $\mathrm{y}$ los costos de internalizar el abastecimiento del mercado externo (invertir), creando una filial dentro de la estructura global de la ET, ${ }^{23}$

\section{La Importancia de una estrategla de desarro- llo expliclta y las rejaciones micro-macro}

Un ejercicio de reflexión sobre las opciones de desarrollo de una realidad económica determinada debe partir por reconocer el papel decisivo que normalmente tiene una estrategia de desarrollo explícita, así como los marcos regulatorios correspondientes. Estos se traducen en un esquema de señalización o régimen de incentivos que condicionan tanto el proceso de toma de decisiones a nivel microeconómico como el desempeño sectorial y macroeconómico resultante, incluidos los grados de inserción en la economía internacional y las madalidades que asume esta última. Esa realidad económica, en proceso de transformación permanente, y la estrategia explícita, como respuesta de la sociedad en determinado momento, dan lugar a un cuadro de influencias recíprocas y reacciones diferenciadas entre el nivel micro y el nivel macro. Esta dinámica se inscribe en la matriz de posibilidades a que se hizo referencia anteriormente y sobre la cual incide un conjunto de variables externas de diversa naturaleza entre las que se pueden citar la ideología, la política, la cultura, el entorno internacional, etc.

La IE en la región ha estado fuertemente condicionada por la propia historia y vicisitudes de la polftica económica de los países latinoamericanos. Es de-

\footnotetext{
${ }^{23}$ Respecto a In nueva teoría de la firma y el concepto de costos de transacción, véanse Caves (1982), Williamson y Winter (1991), Graham y Kruginan (1993).
} 
cir, por la evolución del régimen de incentivos, del marco regulatorio y del propio desempeño macroeconómico que, al actuar sobre escenarios nacionales y unidades productivas con características estructurales distintas, generaron comportamientos microeconómicos y resultantes sectoriales igualmente diferenciados (Katz, 1995).24 Sin duda, el comportamiento sectorial de las filiales extranjeras en la economía regional ha sido marcado fuertemente por: la vigencia prolongada del modelo de industrialización sustitutiva, por una etapa de nacionalización de las actividades de explotación de recursos naturales por la que atravesaron muchos palses latinoamericanos y caribeños entre los años sesenta y setenta y la crisis de la deuda externa de los años ochenta que causó serios desequilibrios en las economías de la región y que dio lugar a los diversos procesos de estabilizacion y ajuste que preludiaron el importante viraje estratégico en las políticas de desarrollo aplicadas por los países de la region al ingresar a la década de 1990.

En esta secuencia histórica hubo etapas y países con diferentes grados de apertura, regulación y control del capital extranjero. Hasta principios de 1980 existía un modelo que ponía el acento en los aspectos regulatorios y de control y otro que se distinguía por su receptividad y estímulo hacia el capital extranjero. Actualmente, se han redefinido todos los regímenes nacionales de tratamiento al capital extranjero, confiriéndoles un carácter promocional y pronunciándose en favor del trato no discriminatorio al inversionista extranjero, de la eliminación de las autorizaciones previas y de los sectores reservados, así como de las restricciones a la repatriación de capitales y a la remisión de utilidades, con muy pocas excepciones. Coherentemente con los propósitos del desarrollo competitivo, en la mayoría de los países latinoamericanos en general no se consideraron en la estrategia de desarrollo ni en el marco regulatorio correspondiente otras modalidades de inversión extranjera distintas de la IED, como la IEP y la IEC, como se verá más adelante.

\footnotetext{
${ }^{24} \mathrm{Katz}$ (1995) reflexiona sobre las relaciones entre la macroeconomía y la microeconomía, y sefiala que la teoría microeconómica convencional (teoría de los precios) no está pensada para admitir que pueden existir dos agentes económicos, de características difenenciadas, que frente a un mismo escenario macroeconónico podrían reaccionar de manera diferente. Esta reflexión parte de la convicción de que los supuestos que informan dicha teoría convencional se contradicen con un escenario teal donde existen interdependencias directas entre agentes economicos individuales, fallas de mercado $\mathrm{e}$ instituciones complementarias del sistema de precios que condicionan la conducta de los agentes econórnicos individuales.
}

Los cambios sucesivos que han experimentado el régimen de incentivos, el marco regulatorio y las variables macroeconómicas, durante las diferentes etapas economicas reseñadas han condicionado el desempeño y el proceso de toma de decisiones a nivel microeconomico de cada uno de los colectivos diferenciados que actúan en determinada realidad nacional de América Latina y el Caribe. Esos colectivos se refieren a subconjuntos de firmas que se diferencian por ciertas características microestructurales como la nacionalidad del capital, el tamaño, el grado de internacionalización de su producción y el de complejidad de sus estructuras y la propia naturaleza técnica de las funciones de produccion respectivas.

El otro conjunto de factores estructurales que hay que considerar se refiere a las características de los propios escenarios económicos nacionales. Dichos factores macroestructurales muchas veces incidieron, con carácter decisivo, en la toma de decisiones a nivel microeconomico frente a los cambios que experimentaron las variables macroeconómicas y el marco regulatorio imperante. Entre estos factores macroestructurales cabe mencionar el tamaño del mercado interno y del mercado ampliado por acuerdos de integración (véase sección II, punto 2), la disponibilidad de recursos naturates explotables (frontera), la proximidad geográfica a los centros más dinámicos de demanda externa, en particular los Estados Unidos, la capacidad productiva y tecnológica acumulada en períodos anteriores (en este caso vinculada al capital extranjero) susceptible por lo tanto de reestructuración a partir del aprovechamiento de dicha capacidad instalada, que en el cálculo económico no viene a ser otra cosa que "costos sumergidos".

Sin pretender hacer una caracterización estructural de los pafses latinoamericanos y de los del Asia en desarrollo, se puede señalar con respecto a las concepciones estratégicas de ambas realidades que en el Asia en desarrollo se gestó una relación armónica entre estilo de industrialización y liberalización comercial, entre desregulación financiera y tratamiento a la inversión extranjera directa y entre absorción de tecnología extranjera y promoción de exportaciones. El resultado fue un incremento de la competitividad internacional no sólo de las empresas extranjeras que operaban en sus territorios sino que además de las propias empresas locales asociadas, subcontratistas, proveedoras o licenciadas por las ETs (propietarias de activos intangibles). Los gobiernos respectivos formularon claras opciones estratégicas de desarrollo y políticas activas que buscaban deliberadamente la transferencia 
efectiva de tecnología como base esencial de un desarrollo competitivo, teniendo como criterio referencial la búsqueda de la convergencia de los intereses corporativos y los objetivos nacionales. En América Latina, por el contrario, la reforma económica ha dado lugar a un dilema hamletiano para las filiales de ETs: desinvertir hasta llegar a dejar de funcionar o, alternativamente, iniciar un proceso de cambios microeconón micos, vinculados a la desverticalización y la especialización, con el prop6sito de seguir operando competitivamente. Esta segunda opción podía emprenderse de manera defensiva (racionalización), minimizando las inversiones y cortando los gastos en personal de manera de sobrevivir a la mayor competencia, o de manera ofensiva (reestructuración), invirtiendo y reorganizándose de forma de llegar a cumplir una función específica en el contexto del esquema de producción internacional de la casa matriz. Cabe, no obstante, señalar que este đỉlema microeconómico se produce en un escenario regional caracterizado mayormente por la pasividad de los gobiernos y la neutralidad de sus políticas (Mortimore, 1995a). Esta actitud se contradice con los usos y prácticas de los propios países desarrollados cuyos gobiernos han mantenido una actitud militante en favor del desarrollo competitivo de sus empresas pero también suficientemente ingeniosa como para evitar los peligros de la asistencia indiscriminada, permanente y sin compromiso del empresario (Vera-Vassallo, 1995b). ${ }^{25}$

\section{Las lecelones de la experiencla macroeconómica en la región}

La experiencia regional parece haber demostrado que cuando la apertura de la cuenta de capitales es muy abrupta y se produce una entrada masiva de capitales externos, el déficit en cuenta corriente puede asumir proporciones que afecten los equilibrios macroeconómicos y que, además, sean difícilmente sustentables en el mediano plazo. La sola capacidad de captar volúmenes importantes de recursos financieros externos no asegura en forma automática el fortalecimiento de los procesos internos de ahorro-inversión y, menos aún, la trascendencia dinámica hacia el binomio progreso téc-

\footnotetext{
29 Vera-Vassallo (1995b), en el punto 4 relativo a la promoción de la competitividad en los países de la 0 Cos, identifica 879 programas de apoyo industrial en dichos países, para el período 1986-1989, con un costo neto gubernamental promedio anual de 66 mil millones de dólares, lo que representa aproximadamente el $2.5 \%$ del valor agregado anual del sector manufacturero de los paises de la OCDE.
}

nico-competitividad internacional. Las entradas masivas de capitales externos pueden afectar negativamente dos variables claves para la asignacion eficiente de recursos: el tipo de cambio y la tasa de interés reales.

Lo anterior parece confirmarse cuando observamos algunos indicadores pertinentes para la región en su conjunto. El balance de bienes para América Latina y el Caribe ha pasado de un superávit de +27.4 miles de millones de dólares estadounidenses en 1990 a un déficit de -15.2 miles de millones en 1994. El saldo del balance en cuenta corriente ha empeorado en el curso de todo el quinquenio, pasando de -6.2 miles de millones de dolares en 1990 a -50 miles de millones en 1994. ${ }^{26}$ Estos déficit en el comercio de bienes y en la cuenta corriente del balance de pagos regional se redujeron $(+2.3$ y -35.5 miles de millones respectivamente) en 1995, luego de la crisis mexicana y de las correspondientes medidas correctivas y de la evolución fayorable de los precios internacionales tanto de los productos básicos como de los industriales (commodities). El índice del tipo de cambio real efectivo de las exportaciones (TCREX) en 1994 estaba por debajo del nivel mostrado en 1990 para 14 países de la región -en una muestra de 18 países-, en la mayoría de los casos con descensos superiores a $10 \%$. Si bien la política monetaria de los países latinoamericanos en el período 1990-1994 se ha visto facilitada por las evidentes mejoras en la gestion fiscal, los desafíos por mantener una expansión monetaria compatible con las metas de crecimiento e inflacion han seguido vinculados al flujo de capitales extranjeros. Las tasas de interés internas han tenido que lidiar con el conflicto existente entre la evolución de la competitividad, las metas monetarias y el financiamiento del déficit en cuenta corriente del balance de pagos. En la mayoría de los casos, en este primer quinquenio de los años noventa ha prevalecido el objetivo de estabilizar los precios, to que ha agudizado la evolución desfavorable del tipo de cambio y la tasa de interés reales. Ante la apertura de la cuenta de capitales, no se han igualado las tasas de interés interna y externa, como podría sugerir un modelo estático y sin imperfecciones de mercado. Es decir, ha continuado el cambio de los precios relativos en favor de los bienes no transables, lo que es un

\footnotetext{
${ }^{26}$ El balance contercial de México pasó de -11 mil millones de d6lares de Estados Unidos en 1990 a -18.5 mil millones en 1994 , mientras el balance en cuenta corriente pasaba de -8.4 a -28.9 miles de millones de dólares en el mismo periodo, con anterioridad a la crisis.
} 
contrasentido si se tienen en cuenta los objetivos primordiales de la nueva estrategia de desarrollo competitivo que están adoptando los paises de la región.

Las experiencias regionales recientes han motivado una gran discusión en torno a la gradualidad y secuencia adecuadas de la apertura financiera. Los hechos están demostrando que frente a procesos de liberalización económica, los mercados financieros se ajustan con mucha mayor rapidez que los mercados reales. Es decir, las tendencias derivadas hacia la apreciación del tipo de cambio, estimuladas por la liberalización financiera, son más rápidas que la tendencia a la desvalorización cambiaria que promueve la apertura comercial, con los efectos consiguientes sobre los precios relativos y sobre los equilibrios macroeconómicos. En este sentido, la experiencia tegional parece indicar que la apertura de la cuenta de capitales hacia el exterior debería haberse realizado con posterioridad a la liberalización comercial y a la desregulación y reforma financiera internas. En el curso de la reforma comercial habría que mantener un control estricto de los flujos financieros externos, sobre todo de los capitales que son por esencia especulativos y altamente volatiles, para evitar su incidencia en la revaluación del tipo de cambio y sus efectos adversos en el comercio exterior y en la inversión, en especial en los productos transables (CEPAL, 1995a).

\section{La transferencia internacional de tecnología: modalidades y características}

La tecnología de proceso y de producto, los conocimientos gerenciales, el diseño y los estándares, los métodos de producción y organización del trabajo, el control de la calidad y la gestión y el mercadeo, entre otros aspectos que componen el paquete tecnologico, son potencialmente transferibles a través de las fronteras nacionales conforme a diversas modalidades que tienen relación con las actividades de las ETs y con su papel preponderante en la generacion, aplicación y comercialización de estos activos intangibles. ${ }^{27}$ Para comprender mejor este proceso de transferencia es necesario prestar atención, por un lado, a las implicaciones que tienen las diversas modalidades de transferencia a que se aludía anteriormente $y$, por otro lado, a las caracteristicas que presenta la transferencia internacional de tecnología a los países de ALC, sea que se

${ }^{27}$ Otra manera de acceder al progreso técnico es el desarrollo cientifico y tecnológico doméstico, asunto al que no se va a hacer referencia pues escapa a los propósitos de este artículo. trate de una operación intrafirma (entre matriz y filial) o de una operación que tiene como destinatario a una empresa local.

Entre las modalidades de transferencia asociadas a las actividades de las ETs pueden identificarse las siguientes:

i) tecnologia vinculada al capital (equity related technology) a través de diversos niveles de participación de la IED en filiales cuya composición patrimonial puede ir desde la propiectad extranjera total hasta empresas conjuntas (joint venture) con diversas proporciones de capital nacional y extranjero.

ii) tecnología vinculada a diversas modalidades de contratación interempresarial (technology contractual arrangements) como licencias, franquicias, contratos de gerencia, consultorlas o asistencia técnica, contratos llave en mano, subcontratación internacional, servicios de control de calidad y estándares, entre otros. ${ }^{28}$ Estas modalidades se denominan también formas no convencionales de inversión extranjera que no suponen aporte de capital (non-equity forms of investment).

iii) tecnología incorporada (embodied technology) en bienes de capital y bienes intermedios.

En el primer caso, hay un uso cautivo de la tecnología en el proceso de expansión de la producción internacional; es decir, la ET no pierde la propiedad ni el control de ese activo cuyo retorno está incluido o se da conjuntamente con las remesas de utilidades. La tecnología se transfiere desde la matriz hacia la filial pero no necesariamente da como resultado una transferencia a terceras partes o difusión al resto del aparato productivo, salvo a través de la formación de personal calificado y los posibles efectos indirectos (spillovers) sobre los eslabonamientos hacia adelante y hacia atrás. En el segundo caso hay una transferencia propiamente dicha a la empresa compradora y un pago explícito en la forma de regalías, derechos, comisiones, etc. La difusion al resto del aparato productivo es más factible, en especial cuando la empresa receptora es propiedad total o parcial de capitales locales. Esto viene a ser condición necesaria pero no suficiente. En el tercer caso, se trata de una operación comercial de bienes tangibles que tienen un precio en el mercado que constituye una retribución por los contenidos materiales y los contenidos tecnológicos incorporados en dichos bienes. La adquisición de maquinaria y equipos es la fuente principal de incorporación

\footnotetext{
${ }^{28}$ Es cecir, todo aquello que pertenece a la esfera de la inversión extranjera indirecta denominada cuasi accionaria (IEC).
} 
de tecnología, en particular en el caso de las empresas más tradicionales, como demuestra un estudio reciente de Rozas (1995). Al usarse productivamente estos bienes, demandan servicios de ingeniería locales. Al comienzo, con propósitos de adaptación a las características y circunstancias de la economía local; luego, con fines de reparación y mantenimiento, lo que a la postre permite avanzar hacia actividades de innovación. Este desarrollo de la ingeniería significa un aprendizaje industrial y tecnológico cuya internalización será proporcional a la cantidad y calidad de la inversión real (léase importación de bienes de capital), pero también al desarrollo institucional de la economfa receptora y, por lo tanto, a su capacidad social de absorción. Esta vá de transferencia depende más de la conducción macroeconómica del país y del marco regulatorio que de la capacidad de negociación con las ETs.

Las modalidades de transferencia tecnológica identificadas pueden presentarse de manera simultánea y combinada. De hecho, existe una clara tendencia en las ETs a introducir contratos intrafirma de transferencia de tecnología en sus operaciones de IED. Es decir, contratos entre matriz y filial o entre filiales. ${ }^{29}$ Estos tipos de contratos vienen a constituir un excelente instrumento para maximizar los objetivos globales de las ETs, sobre todo en lo que se refiere a la tasa de ganancia (Naciones UniđasicET, 1987). En otras palabras, con respecto a la tecnología, la forma preferida por las ETs es su uso cautivo a través de filiales de propiedad total o mayoritaria de la matriz respectiva. ${ }^{30}$ Esto se explica por razones de opción estratégica, pues los contratos intrafirma son especialmente pertinentes cuando es importante la diferenciación de producto, según se trate de marcas registradas o marcas de fábrica, aun cuando el proceso tecnológico no sea muy complejo o sofisticado o cuando el costo de perder el control del conocimiento tecnológico sea muy alto (Naciones Unidas/CET, 1987). También se explica por razones de interés pecuniario, ya que normalmente la ET encuentra imposible obtener la misma renta de ese activo intangible que posee -la tecnología-, que no sea a través del establecimiento de una filial (Naciones Unidas/CET, 1989).

\footnotetext{
${ }^{29}$ En el curso de los años noventa. cerca del $80 \%$ de los pagos internacionales por concepto de royalties, derechos u otras formas de pagos por el uso de la tecnología, han tenido el carácter de intrafirma (UNCTAD, 1994a y 1994b).

${ }^{30}$ La inversa también parece ser cierta, es decir, la transferencia efectiva es más factible en el caso de empresas receptoras con participación aha o total de capital doméstico.
}

\section{La capacidad social de absorción del progreso técnico}

La otra variable determinante de un desarrollo regional competitivo es "la capacidad social de absorción del progreso técnico" del país receptor, lo que está íntimamente ligado a la introducción de cambios y avances institucionales de gran significación en las empresas, en las organizaciones públicas y privadas así como en las políticas gubernamentales pertinentes (Vera-Vassallo, 1995b).

Un nuevo clima cultural se está incubando en la sociedad mundial, el cual expresa la firme convicción de que la capacidad tecnológica de las empresas de un país es la variable crucial de su desempeño competitivo y que esa capacidad es en esencia nacional y puede desarrollarse mediante acciones nacionales (Nelson y Rosemberg, 1993). En este clima ha adquirido particular relevancia, a nivel de la economía en su conjunto, el desarrollo de sistemas nacionales de innovación, cuya finalidad es reforzar la capacidad individual y nacional de negociación, asimilación, aprendizaje e innovación tecnológica.

El sistema nacional de innovación (SNI) puede definirse como la red de agentes económicos y el conjunto de políticas e instituciones que influyen en la introducción y difusión del progreso técnico en la economía. Puesto que en la mayoría de los países en desarrollo la tecnología es básicamente importada, el SNI, en un sentido amplio, comprende las políticas de tratamiento de la IED, las políticas de transferencia de tecnología y otras modalidades de inversion extranjera que no suponen aporte de capital (IEC), y las políticas de derechos de propiedad intelectual y de importación de bienes de capital. En general, el conjunto de normas y regulaciones que ordenan y catalizan el proceso de absorción y difusión del progreso técnico es parte esencial de los SNI.

El sNi también está integradio por la red de agentes e instituciones públicas y privadas que apoyan o emprenden directamente actividades cientificas y tecnológicas, incluidas la investigación y desarrollo (I\&D), la difusión tecnológica y la creación de capital humano, cuya interacción dinámica con la actividad productiva o empresarial debe promoverse. Finalmente, en los SNI influyen de manera directa el clima general de política económica y el régimen de incentivos, ya que éstos determinan en gran medida cuánta inversión o cuánto esfuerzo se emplean para reducir costos, mejorar la calidad y proveer un rango creciente de bienes y servicios competitivos nacional e internacionalmente como resultado de los nueyos avances tecnológicos. 
Los cambios en la organización de las empresas se inscriben en el ámbito de la reestructuración indus- trial y la reingeniería, procesos que son susceptibles de ser promovidos activamente.

\section{V}

\section{Reflexiones sobre los criterios de}

\section{política vigentes y las ausencias existentes}

Es evidente, a partir de las reflexiones anteriores, que la política de inversión extranjera (IE), en su acepción más amplia, y la relativa a su vehículo principal, las empresas transnacionales (ETs), son de importancia vital para el desarrollo de las economías de la región, desde la perspectiva de un desarrollo internacionalmente competitivo. En los párrafos precedentes se han deslizado un conjunto de sugerencias que, como corolario, se desea enfatizar, profundizar o complementar algunas de ellas.

Las principales conclusiones apuntan a la necesidad de un enfoque integral, por dos razones. Primero, porque a fin de maximizar la contribución potencial al desarrollo latinoamericano y caribeño, por parte de las ETs y de las diversas modalidades de IE, es necesario que dicha política se inscriba en el marco de una estrategia explícita de desarrollo nacional, en la cual se asigne un papel específico a la ET, portadora de activos físicos y financieros así como tambiên de activos intangibles, que pertenecen a la esfera del conocimiento organizativo y tecnológico. Estos activos representan la primera prioridad del desarrollo de ALC.

Segundo, porque dicha política debe articularse armónicamente con las características del proceso de liberalización y apertura, con las regulaciones financieras internas, con la política macroeconómica y el régimen de incentivos en favor de la producción de bienes transables internacionalmente, con las políticas de desarrollo y transferencia de tecnologfa y principalmente con las políticas diseñadas para promover la competitividad sistémica. Es decir, a diferencia de 10 que estaría ocurriendo, no se trata de promover indiscriminadamente el ingreso de activos financieros, descuidando el aspecto más importante de dicha contribución potencial que es la transferencia internacional de conocimientos productivos hacia la región. Y, sobre todo, no hay que olvidar que es indispensable que esa transferencia encuentre una capacidad local de absorción tecnológica, y de acumulación de conoci- mientos productivos, que no sólo permita incorporar el progreso técnico y difundido a todo el aparato productivo, sino que ante todo refuerce la capacidad de aprendizaje industrial y tecnologico imprescindible para la fase posterior de innovación endógena e incremento dinámico de la competitividad internacional.

Según la información disponible, en general los cambios de carácter económico e institucional de los países de la región han incrementado su capacidad de atraer indiscriminadamente activos financieros, de muy diversa naturaleza. Esto no siempre ha tenido efectos positivos, en particular sobre el tipo de cambio y la tasa de interés, variables que son de importancia crucial para una asignación eficiente de recursos a través del mercado. Dichas corrientes financieras han tenido un componente cada vez mayor de capitales de corto plazo, por lo general altamente especulativos y de gran volatilidad, to que explica el efecto limitado de estas corrientes sobre los procesos de formación bruta de capital. Según un argumento muy difundido se podría dejar el tipo de cambio liberado a la acción del mercado, es decir, dejarlo caer hasta que el propio mercado efectúe las correcciones necesarias. Estas correcciones operarían a través del aumento del riesgo-país o de las expectativas de devaluacion, con lo que el flujo de capitales se interrumpiría. Sin embargo, la consideración de una situación como ésta depende de la naturaleza de los capitales extranjeros ingresados a las economias latinoamericanas. Si el flujo de recursos externos responde a razones permanentes o estructurales no tendrfa sentido intervenir en favor de un tipo de cambio más alto que el definido por las variables fundamentales de la economía; pero si responde a consideraciones transitorias (como puede ser un programa de privatizaciones) o especulativas (capitales de corto plazo que aprovechan las mayores tasas de interés internas con respecto a las internacionales), entonces, dejar caer el tipo de cambio agudizaría peligrosamente el déficit en cuenta corriente del balance de pagos en 
el mediano plazo, incidiría negativamente en la inversión, tanto nacional como extranjera, y en la producción de bienes transables internacionalmente, es decir, aquellos que tienen relación directa con los propósitos de alcanzar un desarrollo competitivo.

Además, el efecto real de transferencia-absorción de tecnología también ha sido muy moderado, como resultado de estrategias no definidas o incompletas y políticas parciales que privilegian la captación financiera y que en términos de orientación sectorial y tecnológica tienen más bien un carácter neutro y pasivo (Rozas, 1995).

La base de sustentación de la actual postura polftica de la mayoría de los países de América Latina no ha sido el análisis de las características y efectos de las diferentes modalidades de IE incluida, además de la IED, la inversión extranjera indirecta, tanto la IEP como la IEc ${ }^{31}$ No se conocen intentos de privilegiar ETs de determinados países de origen ni de favorecer ciertas modalidades de asociación con las ETs y sus redes regionales de producción y abastecimiento con el proposito de maximizar la transferencia tecnologica $y$, por esa vía, incorporarse al proceso de globalización de la economra mundial.

En la mayoría de los países de la región se observa un desarrollo institucional débil tanto en la esfera pública como en la privada, el Estado adolece de serias limitaciones en su capacidad operativa y en la mayor parte de la región subsiste una capacidad limitada de aprovechamiento de las sinergias potenciales entre los sectores público y privado. Esto, pese a que se trata de dos esferas de actividad cuya concertación e interrelación dinámica es de la mayor importancia para los efectos de disefiar y aplicar la estrategia nacional de desarrollo.

En este contexto, es fácil comprender que lo más importante no son los estatutos, regimenes o códigos nacionales de tratamiento a la IED. Dichos regímenes, en general, constituyen uno de los elementos de un andamiaje institucional que debería cubrir desde el cribado de los recursos que ingresan del exterior, con criterio macroeconómico y de promoción de la inversión real, hasta la creación de un sistema nacional eficiente de innovación. Este sistema debería integrar empresas, instituciones y normas en el marco de una

\footnotetext{
${ }^{31}$ No se hace referencia a los movimientos de capitales oficiales y a los créditos bancarios externos, originados en la banca transnacional, pues a pesar de que constituyen un tipo de inversión financiera procecente del exterior, obedecent a una lógica economica y política diferente.
}

política activa de transferencia, aprendizaje y absorción tecnologica, a partir de las contribuciones potenciales de las ETs y la IE, que anticipe una mayor capacidad de innovación y desarrollo tecnotógico endógena.

Pocos paises en desarrollo han prestado atención a las políticas de promoción de las inversiones directas en el exterior (IRD en el exterior) por razones ligadas a una tradición de limitaciones en la disponibilidad de divisas y capitales. Sin embargo, algunas economías del Asia en desartollo han comenzado a destacar las ventajas que para sus empresas domésticas derivan de un mejor acceso a los mercados y recursos externos, de beneficiarse de sus propios procesos de reestructuración competitiva o de la búsqueda de asociación a sistemas nacientes de producción internacional. En América Latina se está reiniciando una experiencia de larga data con el reconocimiento de la importancia de esta opción estratégica que debe abrirse para las empresas de la región si no se quiere correr el riesgo de malograr su desarrollo competitivo. Destacan los recientes esfuerzos de Chile que ha comenzado a seguirle los pasos a México, que tiene una larga tradición de inversiones en América Central y Estados Unidos, y a Brasil, importante inversionista dentro de la región y en el resto del mundo, que parece reiniciar su IED en el exterior con el impulso del MERCosur. Una política nacional en esta esfera debe conjugarse con el esquema general de liberalización y apertura y puede contribuir, si se acompaña de una buena gestión monetaria, al manejo de las tendencias a la apreciación del tipo de cambio (UNCTAD, 1995).

Con respecto al tratamiento de la IED, se observa en la mayoría de las economías de la región la ausencia de políticas selectivas tendientes a influir en la configuración de la estructura productiva en lo que respecta a distribución espacial, composición sectorial, contenido tecnológico, orientación hacia afuera y otros propósitos de desarrollo productivo, con excepción de las medidas vinculadas a la creación de zonas de procesamiento de exportaciones. Desde esta perspectiva, se podrían concebir dos tipos de regímenes especiales, ambos basados en la aplicación del binomio "incentivos-requisitos de comportamiento" otorgados en forma biunívoca, es decir, el uno asociado al otro y con cierto horizonte temporal predefinido. El primero podría ser un régimen especial negociado a partir de licitaciones oficiales de determinadas actividades internacionalmente competitivas, intensivas en tecnología y con una base de sustentación apoyada en la existencia de una oferta o demanda doméstica de determinados bienes intermedios o finales, por ejemplo, 
la producción de bienes intermedios y de capital para la explotación primaria de algún recurso natural (actividad minera o pesquera). A partir de la licitación podra haber una negociación individual caso a caso (Naciones Unidas, 1992; Morán, 1991, y Guisinger, 1992). El segundo sería un régimen especial automático basado en un sistema de incentivos automáticos a desempeños específicos (Agosín, 1993) que tendría la ventaja de despersonalizar su otorgamiento y evitar las posibilidades de corrupción. Las políticas selectivas de este tipo podrían acercar a la región a ensayos seme- jantes a los existentes en países desarrollados y algunos en desarrollo, particularmente en lo que se refiere a una transferencia efectiva de tecnología. Los regímenes propuestos, en la medida que no atentan contra el artículo III (trato nacional) y el artículo XI (prohibición de restricciones suantitativas) del Acuerdo General de Aranceles y Comercio (GATT) no son incompatibles con la normativa internacional, aun sin apelar a las cláusulas de salvaguarda pertinentes cuando se trata de países en desarrollo como los latinoamericanos y caribeños.

\section{Bibliografia}

Agosin, Manuel (1993): La política comercial y la transformación productiva, Santiago de Chile, Úniversidad de Chile, Departamento de Economia, agosto, mimeo.

Banco Mundial (1993): World Debr Tables. External Finance for Developing Countries. Analysis and Summary Tables 19931994. vol. I. Washington, D.C., diciembre.

Bielschowsky, R. y G. Stumpo (1995): Empresas transnacionales manufactureras en cuatro estilos de reestructuracion en América Latina. Los casos de Argentina, Brasil, Chile y México después de la sustitución de importaciones, Desartollo productivo, $\mathrm{N}^{\mathrm{2}} 20$, LC/G.1857, Santiago de Chile, Comisión Económica para América Latina y el Caribe (CEPAL), mayo.

Cantwetl; J. (1991): A survey of theories of international production, C.N. Pitelis y R. Sudgen (eds.). The Nature of the Transnational Firm, Londres, Routledge.

Caves, R. (1982): Multinational Enterprise and Economic Analysis, Cambridge, Cambridge University Press.

Cepal (Comisión Económica para América latina y el Caribe) (1994): El regionalisnto abierto de Anérica Latina y el Ca ribe. La integración económica al senvicio de la transformación productiva con equidad, LC/G.1801/Rev,1-P, Santingo de Chile, Publicación de las Naciones Unidas, $\mathrm{N}^{0}$ de venta S.94.1I.G.3.

(1995a): América Latina y el Caribe: polticas para mejorar la inserción en la economía mutedial, LC/G.1800/Rev. 1. P, Santiago de Chile, Publicación de las Naciones Unidas, $\mathrm{N}^{\circ}$ de venta S.95.II.G.6.

(1995b): Movimientos de capitales: desafios y opciones de polftica. LC/R. 1559, Santiago de Chile.

(1995c): La inversión extratjera en Antérica Lasina y el Caribe Informe 1995, LC/G.1890, Santiago de Chile.

(1995d): Balance preliminar de la econontia de América Latina y el Caribe, 1995, LC/G.1892-P, Santiago de Chile, Publicaciones de las Naciones Unidas, $\mathrm{N}^{\circ}$ de venta S.95.II.G.18.

Dunning, J. H. (1993); Multinational Enterprises and the Global Economy, Reading, Mass., Wesley Publishing Company Inc.

FinkJuan, J. y M. Montenegro (1995): Vientos de cambio: los nuevos temas centrales sobre las empresas transmacionales. Documento de trabajo, № 63, LC/BUELL. 146, Buenos Aires, Oficina de la CEPAL en Buenos Aires.

Graham, E. y P. Krugman (1993): Chap.1: The surge of foreign direct investment in the 1980s, K. Froot, (ed), Foreign Direct Investment, Chicago, Ill., The University of Chicago Press.

Guisinger, S. (1992); Rethoric and reality in intemational business;
A note on the effectiveness of incentives, Transnational Corporations, vol.1, $\mathbf{N}^{\circ} 2$, Nueva York, Conterencia de las Naciones Unidas sobre Comercio y Desarrollo (UNCTAD), agosto.

$\mathrm{Kat}, \mathrm{J}$. (1995): Regimen de incentivos, marco regulatorio y comportamiento microeconómico, LC/R. 1561, Santiago de Chile. CEPAL/Centro Intemacional de Investigaciones para el Desarrollo (CIID), julio.

Morán, T.H. (1991): The Impact of Trade-Related investment Meastures on Trade and Development, Nueva York. Naciones Unidas/Centro de las Naciones Unidas sobre las Empresas Transnacionales (CET). Publicación de las Naciones Unidas, $N^{\circ}$ de venta E.91.II.A.19.

Mortimore. M. (1995a): Amterica Lasina frente a la globalizacion. Desarrollo Productivo, $\mathbb{N}^{\circ} 23$, LC/G. 1867, Santiago de Chile, CEPAL.

(1995b): Transforming Sitting Ducks into Flying Geese: The Mextcan Automobile Itdustry, Desarrollo Productivo, No 26 LC/G. 1865, Santiago de Chile, CEPAL.

Naciones Unidas/CET (1987): Transnational Corporations and Technology Transfer: Effects and Policy Issues, Nueva York. Publicación de las Naciones Unidas, $N^{\circ}$ de venta E.87.Il.A.4. (1989): Las empresas inansnacionales en el desarrollo mundial, Tendencias y perspectivas, Nueva York. Publicación de las Naciones Unidas, $\mathrm{N}^{\mathrm{*}}$ de venta S.88.II.A.7.

Naciones Unidas (1992): The Determinants of Foreign Direct investment. A Survey of the Evidence, Nueva York. Publicación de las Naciones Unidas, $\mathrm{N}^{\circ}$ de venta E.92.Il.A.2.

Nelson, R. R. y N. Rosemberg (1993): Technical innovation and national systems, R. Nelson (ed.), National Innovation Systems. A Comparative Antalysis, Oxford, Reino Unido, Oxford University Press.

Pitelis, C. N. y R. Sugden (eds.) (1991): On the theory of the transnational firm. The Nature of the Transnational Firm, Londres, Routledge.

Ramos, J. (1993): Crecimiento, crisis y vitaje estratégico, Revisto de la CEPAL, N* 50, LC/G, 1767-P, Suntiago de Chile, CEPAL, agosto.

Rozas, P. (1995): Transferencia de tecnología en países asiáticos y latinoamericanos: diferencias y semejanzns, Santiago de Chile, CEPAL, noviembre, mimeo.

Sigmund, P. E. (1980): Multinationals in Latin America. The Politics of Nationalization, Madison, Wisc., The University Wisconsin Press.

UNCTAD, División de Empresas Transnacionales e Inversión (1994a) World Investment Rcport 1994: Transnational Corporations, 
Employment and the Workplace. An Executive Sumthtary, Nueva York, Naciones Unídas, Publicación de las Naciones Unidas, $N^{\circ}$ de venta E.94.II,A.14, agosto.

(1994b): World Investment Report 1994, Transnational Corporations. Employment and the Workplace, Nueva York, Naciones Unidas. Publicación de las Naciones Unidas, $N^{a}$ de venta E.94.IL.A.14.

(1995): World Investment Report 1995. Transnational Corporations Competitiveness, Nueva York, Naciones Unidas. Publicación de las Naciones Unidas, $N^{\circ}$ de venta E.95.II.A.9, noviembre.
Vera-Vassallo, A. (1995a): Tecnologia, competitividad internacional y desarrollo productivo en America Latina y el Caribe: algunas comparaciones con el Asia en desarrollo, Revista de Economia, vol. XVIII, N 35-36, Lima, Pontificia Universidad Catolica del Penú, julio-diciembre.

(1995b): La importancia de la tecnología en el desarrollo de America Latina y el Caribe, Apuntes Revista de Ciencias Sociales, $\mathrm{N}^{\circ} 36$, Lima, Universidad del Pacfico, Centro de Investigacion, primer semestre.

Williamson, O. y S. Winter (eds.) (1991): The Nature of the Firm: Origins, Evolution and Development, Oxford Reino Unido, Oxford University Press. 